\title{
Validation of Spanish Language Evaluation Instruments for Body Dysmorphic Disorder and the Dysmorphic Concern Construct
}

\section{Cristina Senín-Calderón ${ }^{1 *}$, María Valdés-Díaz ${ }^{2}, M^{a}$ M. Benítez-Hernández², $M^{a}$ C. Núñez-Gaitán ${ }^{2}$, Salvador Perona-Garcelán ${ }^{2,3}$, Rafael Martínez-Cervantes ${ }^{2}$ and Juan F. Rodríguez-Testal'}

${ }^{1}$ Department of Psychology, University of Cádiz, Cádiz, Spain, ${ }^{2}$ Personality, Evaluation and Psychological Treatment Department, University of Seville, Seville, Spain, ${ }^{3}$ Virgen del Rocío Outpatient Mental Hospital, Andalusian Health-Care, Seville, Spain

OPEN ACCESS

Edited by:

Min Liu,

University of Hawaii at Manoa,

United States

Reviewed by:

Donald Sharpe,

University of Regina, Canada

Victoria Savalei,

University of British Columbia

Canada

*Correspondence:

Cristina Senín-Calderón

cristina.senin@uca.es

Specialty section: This article was submitted to

Quantitative Psychology and Measurement, a section of the journal

Frontiers in Psychology

Received: 13 February 2017

Accepted: 15 June 2017

Published: 30 June 2017

Citation:

Senín-Calderón C, Valdés-Díaz M,

Benítez-Hernández MM,

Núñez-Gaitán MC,

Perona-Garcelán S,

Martínez-Cervantes $R$ and

Rodríguez-Testal JF (2017) Validation

of Spanish Language Evaluation

Instruments for Body Dysmorphic

Disorder and the Dysmorphic

Concern Construct.

Front. Psychol. 8:1107.

doi: 10.3389/fpsyg.2017.01107
Dysmorphic concern (DC) refers to excessive preoccupation with a slight or imagined defect in physical appearance with social avoidance and behavior directed at controlling the defect in appearance. This study attempted to adapt the factor structure of two instruments that cover the DC construct, the Dysmorphic Concern Questionnaire (DCQ) and the Body Dysmorphic Disorder Examination Self-Report (BDDE-SR), to Spanish and establish their psychometric properties. A total of 920 subjects $(62.7 \%$ women, $M_{\text {age }}=32.44$ years) participated. Exploratory and Confirmatory Factor Analysis of both scales found adequate goodness of fit indices. A one-dimensional structure was found for the DCQ and two first-order factors (dissatisfaction/preoccupation with body image (BI) and $\mathrm{BI}$ avoidance behavior) were identified for the BDDE-SR. The psychometric test-retest reliability and validity properties (content, convergent, and discriminant) were satisfactory. It is suggested that the DC construct includes both cognitive and behavioral aspects and may represent a continuum of severity with Body Dysmorphic Disorder at the end.

Keywords: dysmorphic concern, DCQ, BDDE-SR, risk, Body Dysmorphic Disorder

\section{INTRODUCTION}

The study of alterations in body image (BI) is justified in a Western society where physical appearance is considered an indicator of social and professional success. An ideal of beauty (thin, young, sculpted, or worked on bodies, etc.) is transferred by communications media, by peers, family or partner, and sinks into the self-consciousness of people in general and the youngest in particular (Rodríguez-Testal, 2013).

Alterations in $\mathrm{BI}$ include other diagnostic expressions apart from Eating Disorders, especially Body Dysmorphic Disorder (BDD) (Cash and Smolak, 2011; Rodríguez-Testal, 2013). BDD is a preoccupation with barely perceptible or imagined flaws in physical appearance believed to be deformed or unattractive. Preoccupation means spending long times thinking about the perceived defect. BDD also involves difficulty in controlling/resisting behaviors caused by preoccupation (e.g., checking defects), and significant distress or impaired functioning. Presence of BDD is low, from 0.7 to $3.2 \%$ of the general population (Barahmand and Shahbazi, 2015; Schieber et al., 2015), although it is suspected that persons with this type of alteration do not seek help (a sort 
of silent disorder) or do so only in the severest of cases due to its social, family or personal consequences (Castle et al., 2004).

Thus the dysmorphic concern (DC) dimensional construct (Oosthuizen et al., 1998), refers to excessive preoccupation with a slight or imagined defect in physical appearance (Oosthuizen et al., 1998; Onden-Lim and Grisham, 2013). As given in the DSM-5 (American Psychiatric Association [APA], 2013, p. 247), has been proposed as a wider concept, beyond concern for physical appearance in general linked to normative body dissatisfaction (Rodin et al., 1984). It has been suggested that in addition to the slight or imagined defect, this construct should also be extended to the presence of social avoidance and behaviors directed at controlling the defect in appearance (Onden-Lim and Grisham, 2013). From this viewpoint, the DC construct would more closely approach the diagnostic definition of BDD, and perhaps one of more clinical usefulness.

In any case, the evaluation of the DC construct may be useful for identifying BDD proneness or risk. This is particularly important among young people, as it is known that the first symptoms of BDD start in adolescence at around 16 years of age (Phillips et al., 2005; Bjornsson et al., 2013). One study found that $9 \%$ of young people with a mean age of 12 could be at risk of developing BDD (Mastro et al., 2016). Data suggest that the presence of BDD in university students is from 2.3 to $5.8 \%$ (Bartsch, 2007; Taqui et al., 2008). When DC was measured in university students, the figure was over $19 \%$ of those evaluated (Barahmand and Shahbazi, 2015). However, although all cases of DC do not lead necessarily to a formal diagnosis of BDD, this does not mean exemption from distress, and it may define a situation of personal risk.

Some results have suggested that DC may not be an automatic process related to a personal standard, but rather a partially conscious bias toward stimuli related to appearance (OndenLim et al., 2012), conditioned by the need to fit into the social standard of body and appearance, and possibly mediated by sensitivity to rejection by others (Lavell et al., 2014b). It is possible that social anxiety, experiences of victimization and other variables like perfectionism, contribute to developing and maintaining these DC (Bartsch, 2007; Anson et al., 2012; Lavell et al., 2014a,b; Webb et al., 2015; Mastro et al., 2016). Since BDD (and DC) are located in the obsessivecompulsive spectrum, it is expectable for common cognitive processes, such as rumination or high self-consciousness, to also contribute to their genesis and maintenance, as in other disorders in this group (Onden-Lim et al., 2012; Onden-Lim and Grisham, 2013; Lavell et al., 2014a). This also occurs in other more specific and emotional symptoms, basically anxiety and depression (Phillips, 2009; Rodríguez-Testal, 2013; Keating et al., 2016).

All mentioned above suggests the need for clinically useful tools for knowing and identifying the processes related to DC (and BDD). Therefore, the following goals are posed: (1) Adapt the factor structure of the Body Dysmorphic Disorder Examination Self-Report (BDDE-SR; Reiter, 1996) and the Dysmorphic Concern Questionnaire (DCQ; Oosthuizen et al., 1998) to Spanish. Both instruments include the DC construct. The DCQ is more general or strictly related to the concept as cognition, while the BDDE-SR has a broader definition which includes preoccupation and negative evaluation of appearance, excessive importance given to appearance in self-evaluation, avoidance of places and activities, body camouflaging, and body checking, (2) Find the psychometric reliability (internal consistency and retest) and validity (content, convergent, and discriminant) properties of the BDDE-SR and DCQ tests, and (3) Analyze the risk of BDD by detecting DC using the BDDE-SR and DCQ.

\section{MATERIALS AND METHODS}

\section{Participants}

The sample consisted of 966 participants (34.12\% university students and $65.88 \%$ non-university general population), $62.7 \%$ women with an average age of $32.44(S D=13.33$; range 18-65 years). The average social class index (SCI) according to Hollingshead (1975) was $48.72(S D=21.81)$ (mean social class).

A total of 46 participants were excluded because they currently had some psychological disorder, leaving a final sample of 920 subjects. The student group was recruited by incidental sampling. The participants from the general population were recruited by snowballing, so the characteristics of these two groups would be close to the general population. Many students put us in contact with relatives and acquaintances (not university students) who, in turn, contacted other friends and acquaintances (not university students). All the participants received an information sheet explaining the general characteristics of the evaluation and signed their consent for participating. The Clinical Research Ethics Committee of Cádiz (University Hospital Puerta del Mar) approved the research. The principles of the World Medical Association (Declaration of Helsinki) were followed.

\section{Instruments}

\section{Demographic and Current Symptom Questionnaire (Tool Developed by Authors)}

This self-evaluation identified the SCI (Hollingshead, 1975), current illnesses, psychopathological antecedents, history and duration of symptoms, psychopharmacological treatments, and use of other drugs.

\section{Body Dysmorphic Disorder Examination Self-Report (Reiter, 1996)}

This 26-item test was designed to evaluate dysmorphic alterations of BI. Items are scored from 0 to 6 , except for Item 16 which is dichotomous (YES/NO). Items 9, 10, 11, and 16 have two parts. The final score is the sum of all the items. A high score shows characteristic indicators of BDD (overvalued ideas and avoidance and checking behaviors associated with negative $\mathrm{BI})$. The psychometric properties of the original version are adequate: test-retest reliability $(r=0.89)$, internal consistency ( $\alpha=0.94)$, and convergent validity with other measures of BI disorders ( $r=0.69-0.83$ ) (Reiter, 1996; Rosen and Ramirez, 1998). 


\section{Goldberg General Health Questionnaire (GHQ-28) Spanish Version by Lobo et al. (1986)}

This is a screening test that gives an overall evaluation of health and social dysfunction. It consists of 28 items grouped in four subscales on somatic symptoms, anxiety, social dysfunction, and severe depression. In this study, the anxiety (GHQ-A), somatic symptoms (GHQ-S), and depression (GHQ-D) subscales were used. It has adequate reliability (test-retest, $r=0.90$ ) and validity (sensitivity from 44 to $100 \%$ and specificity from 74 to $93 \%$ ). In this study, internal consistency for GHQ-A was $\alpha=0.80$, GHQ-D was $\alpha=0.70$ and GHQ-S was $\alpha=0.75$.

\section{Dysmorphic Concern Questionnaire (DCQ; Oosthuizen et al., 1998)}

This questionnaire is comprised of seven items with the characteristic concerns of $\mathrm{BDD}$, for example: ...Been very concerned about some aspect of your physical appearance? It has a Likert-type response format (four choices, from 0 to 3 points). High scores show more preoccupation with physical appearance. The designers of the instrument found internal consistency of $\alpha=0.80-0.88$ and strong correlation with the BDDE (Pavan et al., 2008). Preliminary results for the overall DCQ score in Spanish university students were: $\alpha=0.82$ and retest $r=0.78$ (ValdésDíaz et al., 2013), and correlations were found with measures of alteration of BI (IMAGEN Questionnaire $r=0.61$ ).

\section{The Ruminative Response Scale (RRS; Nolen-Hoeksema and Morrow, 1991), Spanish Version by Hervás (2008)}

This evaluates the presence of a ruminating response pattern. It consists of 22 items distributed in two factors: rumination and reflection. The first represents the negative component of the ruminating style and the second a more adapted component. The Spanish version has shown good retest reliability and internal consistency indices (rumination $\alpha=0.80$, reflection $\alpha=0.74$ ), and adequate factor, convergent and incremental validity. In this study only the rumination factor was applied (REP) with $\alpha=0.77$.

\section{The Cuestionario Imagen [Image Questionnaire] (Solano and Cano, 2010)}

This evaluates dissatisfaction with BI. It is comprised of 38 items (in Likert-type format $0-4$ points) grouped in three factors: cognitive-emotional dissatisfaction (ICOG), perceptive dissatisfaction (IPER), and behavioral dissatisfaction (IBEH). It has satisfactory psychometric indices: $\alpha=0.91$, retest stability $=0.97$ for the total score and validity (construct and convergent: with the BSQ and the CIMEC) (Solano and Cano, 2010). In this study, internal consistency was $\alpha=0.95$ for ICOG; $\alpha=0.87$ for IPER; $\alpha=0.72$ for IBEH.

\section{The Revised Self-consciousness Scale (Scheier and Carver, 1985), Spanish Version by Banos et al. (1990)} This is made up of 22 items which evaluate the tendency of individuals to direct their attention outside or within themselves. It has three factors: (1) Private self-consciousness (PRISC), (2) Public self-consciousness (PUBSC), and (3) social anxiety, which was not used in this study. It has adequate reliability ( $\alpha$ PRISC $=0.75, \alpha$ PUBSC $=0.92$ ), and validity (content and construct). In this study, consistency was $\alpha=0.75$ for PRISC, and $\alpha=0.77$ for PUBSC.

\section{Procedure}

The translation and adaptation of the BDDE-SR and DCQ scales to Spanish were done following the recommendations of Muñiz et al. (2013) using the back-translation method with two translators, one of them familiar with the Spanish culture and the other familiar with the United States. The first translator translated the scales into Spanish and then this translation was translated back into English again. These versions were compared with the original English versions for accuracy.

\section{Data Analysis}

The sample was divided at random into two halves for cross validation of the instruments. Two Exploratory Factor Analyses (EFA), one for the BDDE and another one for the DCQ, were done with Sample $1(n=460)$, on the polychoric correlations matrix with Robust Diagonally Weighted Least Squares (RDWLS) and Direct Oblimin rotation. Three models were tested by Confirmatory Factor Analysis (CFA) with Sample $2(n=460)$, each for the BDDE and DCQ, with the RDWLS method using the asymptotic covariance matrix. Chi squared, Comparative Fit Index (CFI), Non-Normed Fit Index (NNFI), Goodness of Fit Index (GFI), Adjusted Goodness of Fit Index (AGFI), which must be $>0.90$ (Baumgartner and Homburg, 1996) were used to test the overall fit of models. In addition to these indices, the Root Mean Square Error of Approximation (RMSEA) and its confidence interval at $90 \%$, which must be $\leq 0.05$ for a good fit, and between 0.05 and 0.08 for an acceptable fit. The Standardized Root Mean Square Residual (SRMR), which must be $\leq 0.05$ for a good fit, and between 0.05 and 0.10 for an acceptable fit (Schermelleh-Engel and Moosbrugger, 2003), were also calculated.

For descriptive purposes, mean gender and age were compared $(n=920)$ with the BDDE-SR-28 scores (name after elimination of items in CFA) and DCQ, and the quartiles were found for both tests to determine BDD risk.

Cronbach's $\alpha$ and test-retest reliability indices were found. To study the validity of BDDE-SR-28 test content, a jury of experts comprised of 15 clinical psychologists evaluated item adequacy for their respective constructs on a Likert type scale (0-5 points). The Aiken $V$ was found from the average scores of each judge. The criterion of reference for item adequacy was $V>0.70$ (Charter, 2003). For convergent validity, bivariate Pearson's Correlation analyses were conducted. For discriminant validity, a one-way analysis of variance (ANOVA) was done of this variable (subjects at dysmorphic risk or not) with participants in the $\geq 75$ th percentile on the BDDE-SR-28 and the DCQ (subjects at dysmorphic risk) over the factors in the IMAGEN test, the factors on the GHQ-28 test, rumination (RRS) and PRISC and PUBSC (Self-Consciousness Scale). Statistical analyses were done with the SPSS, Lisrel 8.7 (for CFA), and Factor 10.4.01 programs (for EFA; Lorenzo-Seva and Ferrando, 2006). 


\section{RESULTS}

\section{Preliminary Analysis}

The sample was divided into two halves (two groups). The sociodemographic variables (gender, age, and SCI, $p>0.05$ ) and DCQ and BDDE-SR overall measurements $(p>0.05)$, were equivalent in both groups before the psychometric analysis $\left(\right.$ Table $\mathbf{1}^{1}$ ).

\section{Exploratory and Confirmatory Factor Analyses of the BDDE-SR Scale}

An EFA was done of the BDDE-SR test with Sample 1 ( $n=460$ ), which showed adequate values in the KMO (0.92, 95\% CI $=0.920-0.921)$ and Bartlett's sphericity $\left[\chi^{2}(435)=7179.9, p<0.001\right]$ tests. However, Items $1,10 \mathrm{a}$, 12 , and 15 showed communalities below 0.40 . Parallel analysis recommended a two-factor solution. The first factor (related with dissatisfaction/preoccupation with BI) included Items 1, $2,3,4,5,6,7,8,9 \mathrm{a}, 9 \mathrm{~b}, 10 \mathrm{a}, 10 \mathrm{~b}, 11 \mathrm{a}, 11 \mathrm{~b}, 12,13,14,15,22$, 23 , and 26 and the second factor (related with BI avoidance behavior) included Items 16a, 16b, 17, 18, 19, 20, 21, 24, and 25 (the content of these items may be found in the Supplementary Material, Table 1). All items were well represented in the factor they were intended to measure except Items 22 and 23, related to BI avoidance behavior. These two factors explained $55 \%$ of the variance.

The CFA was done with Sample $2(n=460)$. A first-order factor structure was tested with the data from the EFA. Fit indices found were adequate (Model 1, Table 2), although the indices of modification suggested some changes that were considered under the theoretical cover of the model and the approval of the expert judges (transfer of Items 22 and 23 to Factor 2 and elimination of Items $16 \mathrm{a}$ and $16 \mathrm{~b}$ because they showed low factor loading, 0.05 and 0.29 , respectively). The new model analyzed (Model 2, Table 2) with the modifications described had better fit indices than Model 1, although the correlation between factors in both Models 1 and 2 was very high $r=0.87$. Given the high correlation, it was decided to try a one-dimensional model as suggested by the

${ }^{1}$ The descriptive analyses may be found by subsamples "student vs general population" in the Supplementary Material, Table 2. scale's designer (Model 3, Table 2). RMSEA was inadequate and the chi-square found was higher than for Models 1 and 2. The fit indices showed that the model 2 was the best (see Table 2 and Figure 1). Hereinafter this reduced version of the scale is called the BDDE-SR-28.

\section{Exploratory and Confirmatory Factor Analyses of the DCQ Scale}

The EFA of the DCQ showed adequate values for the KMO (0.85, $95 \% \mathrm{CI}=0.83-0.88)$ and Bartlett's sphericity $\left[\chi^{2}(21)=1231.8\right.$, $p<0.001]$ tests. Parallel analysis recommended a one-factor solution with an eigenvalue of 4.21 (explaining $60 \%$ of the variance). The fit indices found after CFA were all adequate: $\chi^{2}(13)=58.79, p<0.001 ; \mathrm{NFI}=0.98$, CFI $=0.98$, $\mathrm{GFI}=0.99$, AGFI $=0.98, \mathrm{SRMR}=0.058$ and $\mathrm{RMSEA}=0.083$ $(\mathrm{CI}=0.062-0.11)$. The factor loading varied from 0.54 to 0.83 (see Figure 2).

\section{Descriptive Analysis}

Statistically significant differences were found between the genders in total scores on the BDDE-SR-28 and DCQ scales, where women had the highest scores on both tests [BDDE-SR-28: $t(787.52)=-6.62, p<0.001$; DCQ: $t(774.31)=-4.19$, $p<0.001]$. The sample was divided into two groups by age $(<27$ and $\geq 27$ years), taking the median in this variable as reference, and the means over the BDDE-SR-28 and DCQ variables were compared. The youngest had a higher mean on the BDDE-SR-28: $t(882.99)=5.47, p<0.001$ and DCQ: $t(866.93)=6.81, p<0.001$. The score quartiles were calculated for both tests to be able to find risk scores and subjects, finding $25 \%$ of the participants in the third quartile ( $\geq 75$ th percentile) on the BDDE-SR-28 and $26.09 \%$ on the DCQ. However, the subjects in the $\geq 75$ th percentile on both tests represented $14.71 \%$ of the sample $(n=136)$. These subjects were considered to be at dysmorphic risk.

\section{Psychometric Properties: Reliability and Validity}

A jury of experts ( $n=15$ clinical psychologists, average clinical experience $=16.36$ years, $S D=10.26$ ) evaluated the validity of the BDDE-SR-28 scale content after eliminating the

TABLE 1 | Comparison of means between Sample 1 and Sample 2 of sociodemographic variables and total scores on DCQ and BDDE-SR

\begin{tabular}{|c|c|c|c|c|}
\hline & $\begin{array}{l}\text { Sample } 1(n=460) \\
M(S D), n(\%)\end{array}$ & $\begin{array}{l}\text { Sample } 2(n=460) \\
M(S D), n(\%)\end{array}$ & $t / \chi^{2}(d f)$ & $p$ \\
\hline Age & $32.52(13.11)$ & $32.37(13.15)$ & 0.17 (918) & 0.866 \\
\hline $\mathrm{SCl}$ & $50.11(22.64)$ & $47.40(21)$ & $0.86(918)$ & 0.391 \\
\hline BDDE-SR (range 0-146) & $32.81(27.44)$ & $31.08(25.42)$ & $0.99(918)$ & 0.321 \\
\hline DCQ (range 0-28) & $3.92(3.63)$ & $3.97(3.54)$ & $-0.23(918)$ & 0.818 \\
\hline Gender & $\begin{array}{l}\text { Men: } 170 \text { (18.5\%) } \\
\text { Women: } 290(31.5 \%)\end{array}$ & $\begin{array}{l}\text { Men: } 173 \text { (18.8\%) } \\
\text { Women: } 287(31.2 \%)\end{array}$ & $0.042(1)$ & 0.838 \\
\hline $\begin{array}{l}\text { Percentile } 75 \text { BDDE-SR } \\
\text { (46 points) }\end{array}$ & $24.35 \%$ & $25.43 \%$ & & \\
\hline $\begin{array}{l}\text { Percentile } 75 \\
\text { DCQ (6 points) }\end{array}$ & $24.35 \%$ & $27.82 \%$ & & \\
\hline
\end{tabular}


TABLE 2 | Fit indices of models analyzed with Confirmatory Factor Analysis: BDDE-SR.

\begin{tabular}{|c|c|c|c|c|c|c|c|c|c|}
\hline Model & $x^{2}$ & $d f$ & $p$ & GFI & NFI & CFI & AGFI & SRMR & RMSEA $(90 \% \mathrm{Cl})$ \\
\hline Model 2: two-factor model with modifications (28 items) & 1300 & 349 & $<0.001$ & 0.99 & 0.97 & 0.98 & 0.99 & 0.064 & $0.077(0.073-0.082)$ \\
\hline
\end{tabular}

*The values in bold indicate that it is the best model.

Items $16 \mathrm{a}$ and 16b, and Items 22 and 23 were transferred to the avoidance behaviors factor. All the items had valid coefficients (Aiken $V$ ) of $V=0.77$ (Item 14) to $V=0.98$ (Item 17).
The psychometric properties were found with the complete sample $(n=920)$. Internal consistency for the total BDDE-SR-28 eliminating the items $16 \mathrm{a}$ and $16 \mathrm{~b}$ was $\alpha=0.94$. The Cronbach's $\alpha$ for the BI preoccupation/dissatisfaction factor

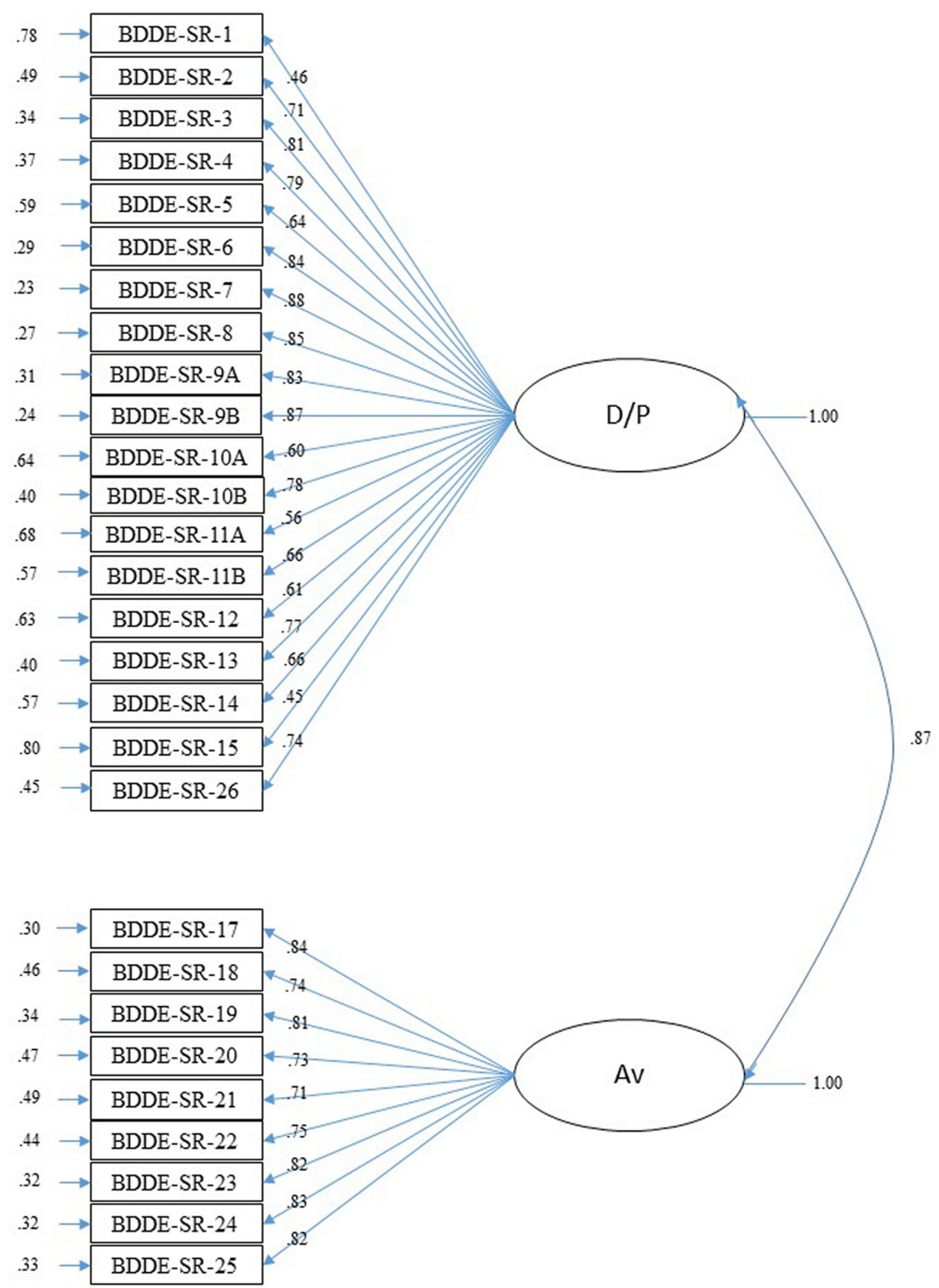

FIGURE 1 | Confirmatory Factor Analysis for BDDE-SR-28. Completely standardized solution. D/P, dissatisfaction/preoccupation with body image; AV, body image avoidance behaviors. 


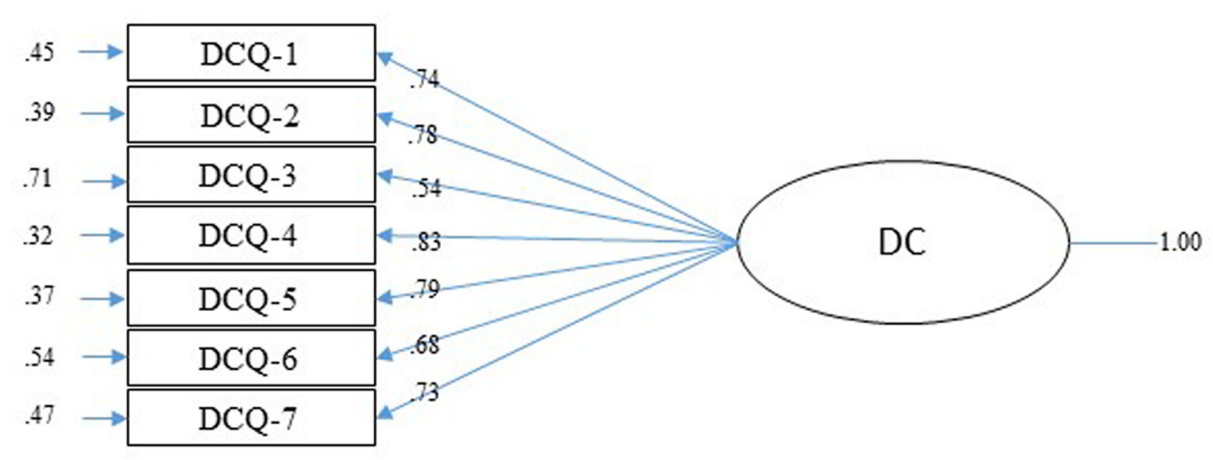

FIGURE 2 | Confirmatory Factor Analysis of DCQ. Completely standardized solution.

(19 items) was $\alpha=0.93$ and for the BI avoidance factor (nine items) was $\alpha=0.87$. Retest reliability $=0.96$ (average interval of 1 month). Internal consistency for the DCQ was $\alpha=0.85$ and retest reliability $=0.87$ (average interval of 1 month).

To determine convergent validity, a Pearson's correlation analysis was done of the IMAGEN subscales (ICOG, IPER, IBEH), the BDDE-SR-28 dissatisfaction/preoccupation and avoidance behaviors factors and the total DCQ scale score. Table 3 shows the positive statistically significant correlations of all the measures. Particularly strong is the relationship between DCQ and the BDDE-SR-28 dissatisfaction/preoccupation factor, and between this one and the IMAGEN test ICOG factor.

To analyze the discriminant validity of both measures, means of the subjects considered at high dysmorphic risk $(n=136)$ vs not at risk $(n=784)$ and the IMAGEN, GHQ-28, REP, and self-consciousness factors were compared. The results showed statistically significant differences in all the comparisons with high-risk subjects scoring highest on the factors in the IMAGEN: ICOG $t(918)=-16.01, p<0.001$; IPER $t(918)=-12.48$; $p<0.001$; IBEH $t(918)=-10.44, p<0.001$ and on the rest of the measures: GHQ-A: $t(918)=-9.02, p<0.001$; GHQ-S: $t(918)=-8.60, p<0.001$; GHQ-D: $t(918)=-7.45, p<0.001$, REP (RRS): $t(918)=-11.02, p<0.001$; PUBSC: $t(918)=-8.80$, $p<0.001$; PRISC: $t(918)=-7.98, p<0.001$.

\section{DISCUSSION}

The purpose of this study was to adapt the DCQ and BDDE-SR scales to Spanish and study their factor structures, to find their psychometric properties and analyze BDD risk by detecting DC with these tests.

The results of EFA and CFA corroborated the one-dimensional structure of the DCQ for which adequate goodness-of-fit indices were found. For the BDDE-SR, both analyses determined the existence of two different but very closely related factors. A one-dimensional model was tested, however, the fit indices were not entirely adequate. In spite of this, the one-dimensional option may not be discarded. A one dimensional model is more restricted than a model with more factors, and therefore, it is to be expected that such a wide scale have a less parsimonious fit, unlike the DCQ which fits one-dimensionally very well because it is a very short scale. However, in view of its better goodness-of-fit indices and the suggestions of the experts (keeping in mind the theoretical corpus), we decided on the model with two first-order factors. A factor more related to the cognitive-emotional component of BI (preoccupation and dissatisfaction) and another more related to BI avoidance behaviors were found. Both components were close to the BI dimensions suggested by Cash and Smolak (2011). One was an evaluative or comparative component concentrating on pleasing/displeasing and satisfaction/dissatisfaction with physical

TABLE 3 | Pearson's correlation matrix of DCQ, BDDE-SR-28, and IMAGEN domain scores.

\begin{tabular}{|c|c|c|c|c|c|c|}
\hline Variables & 1 & 2 & 3 & 4 & 5 & 6 \\
\hline 1. D/P BDDE-SR-28 & - & & & & & \\
\hline 2. AV BDDE-SR-28 & $0.739 * *$ & - & & & & \\
\hline 3. DCQ & $0.657^{* *}$ & $0.557^{* *}$ & - & & & \\
\hline 4. ICOG & $0.647^{* *}$ & $0.603^{* *}$ & $0.526^{* *}$ & - & & \\
\hline 5. IPER & $0.435^{* *}$ & $0.484^{* *}$ & $0.366^{* *}$ & $0.648^{* *}$ & - & \\
\hline 6. IBEH & $0.413^{* *}$ & $0.420^{* *}$ & $0.394^{* *}$ & $0.487^{* *}$ & $0.356^{* *}$ & - \\
\hline Mean & 25.36 & 7.67 & 3.94 & 25.87 & 3.30 & 0.70 \\
\hline$S D$ & 18.18 & 8.96 & 3.58 & 19.47 & 5.42 & 1.91 \\
\hline
\end{tabular}

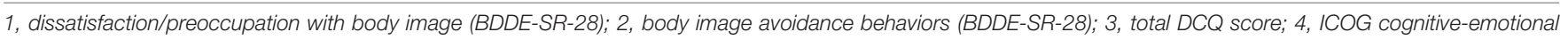
dissatisfaction (IMAGEN); 5, IPER perceptive dissatisfaction (IMAGEN); 6, IBEH dissatisfaction behaviors (IMAGEN). All values are ** $p<0.001$. 
appearance, and the other a component related to dedication or investment in appearance, in this case, more clearly behavioral: care, attention and body-related behavior.

CFA of the BDDE-SR recommended elimination of two items because of their low factor loading (16a and 16b). These items are the only ones that have a different response format (YES/NO answer choice) and it could be problematic to consider them with the rest of the items which have scores ranging from 0 to 6 points. After these results and evaluation by experts of the adequacy of the items with their respective constructs, we validated a reduced Spanish version of the BDDE-SR with adequate goodness-of-fit indices and psychometric properties, the BDDE-SR-28.

On the other hand, even though Reiter (1996) was based on a one-dimensional model, the 10 items he considered for the diagnosis of BDD would be represented in six items pertaining to the factor identified as dissatisfaction/preoccupation, and four pertaining to the factor named avoidance. Consequently, neither the consideration of the two factors nor the elimination of two items affected to the original test.

Adequate reliability indicators were found for both the DCQ and the BDDE-SR-28 in a general population sample not formed exclusively of university students. Internal consistency was satisfactory for both scales and the retest stability showed good characteristics over an average time interval of 1 month. Validity indicators were adequate. Both instruments showed similar results and in the direction predicted for convergent validity, especially the relationship between the BDDE-SR-28 and DCQ dissatisfaction/preoccupation factor and the IMAGEN test cognitive-emotional dissatisfaction factor. Because of the DCQ's adequate psychometric properties and high correlations with the IMAGEN and BDDE-SR-28 factors, we can recommend its application as a screening scale for evaluating DC.

In discriminant validity, the highest scores (75th percentile in DCQ and total BDDE-SR-21) were significantly related to high BI dissatisfaction (IMAGEN test), greater presence of emotional symptoms (GHQ-A, GHQ-D, and GHQ-S), rumination (REP), and self-consciousness (PRISC and PUBSC) (Phillips, 2009; Onden-Lim et al., 2012; Onden-Lim and Grisham, 2013; Rodríguez-Testal, 2013; Lavell et al., 2014a). Therefore, the adapted measures may be considered useful for specifically cognitive evaluation of DC (DCQ), as well as broader and behavioral (BDDE-SR-28).

With the adaptation of these tests, it was also intended to back the "dysmorphic concern" dimensional construct beyond BI dissatisfaction, in which preoccupation for one or more perceived defects and a series of associated behaviors are present on a continuum where BDD would be at the far end (Oosthuizen et al., 1998; Onden-Lim and Grisham, 2013). In view of the results, we consider both the BDDE-SR-28 and the DCQ adequate for detecting $\mathrm{DC}$ in the general population, and therefore, risk of developing BDD. The quartiles on both tests show that a significant part of the sample (from 25 to $26 \%$ ) had DC, higher than what has been found in other studies with participants under 20 years of age (Barahmand and Shahbazi, 2015) and close to other studies in which only university students participated (Bartsch, 2007). Keeping in mind that in our sample the age range was wider, this percentage of persons with DC must be considered high. Therefore, risk of BDD should not be set exclusively at the 75th percentile, but with coincidence in this percentile in both tests, since this is already clearly showing suffering and distress. Following this criterion, $14.71 \%$ of the sample had significant scores on both tests, much closer to the results that include university students, although with gender differences for both scales, not usually found for BDD (Phillipou and Castle, 2015), although there are studies that show a higher prevalence in women (Buhlmann et al., 2010; Schieber et al., 2015). Results for differences in age coincide with those in the literature (for a review, see Veale et al., 2016), in which the youngest are at the greatest risk of developing BDD.

This study had some limitations that should be born in mind. It was a cross-sectional design with no follow-up of subjects found with DC. It would have been interesting to have followed up on them to find out how many of those subjects at risk actually develop BDD. It would also be very important to establish the level of distress or suffering of individuals with DC, regardless of whether a BDD diagnosis is made at some time, so the sense of the construct can be analyzed in depth and described in detail. Apart from this, and to analyze the validity of criterion, a group of subjects diagnosed with BDD could have been included to find out if the DCQ and especially the BDDE-SR-28 tests were able to discriminate between the clinical and non-clinical populations and the clinical population and one identified as "dysmorphic risk." Reiter (1996) demonstrated that the BDDE-SR scale was able to predict the clinical state of subjects diagnosed with BDD. Other researchers are encouraged to consider this possibility with the reduced version adapted to Spanish which this study has contributed. Thus in future studies, the predictive ability of these instruments and the DC construct will be tested for diagnosis of BDD as well as detailed description of the functional and emotional characteristics of DC.

In spite of its limitations, this study does have some strengths. In Spain, many adapted instruments are available for evaluating negative BI, but they are closer to detection of eating disorders. There are hardly any self-reported measures validated with Spanish samples for detection of BDD, even though it is a more prevalent disorder than anorexia or bulimia nervosa (Hoek, 2006). Most individuals with BDD do not seek psychological treatment for their problem (Castle et al., 2004), and it is more common for them to seek medical treatment (e.g., plastic surgery, dermatological or dental treatments), which far from improving their problem, contribute to its becoming chronic (Sarwer and Crerand, 2008; Veale et al., 2016). The BDDE-SR has been employed as a diagnostic instrument for BDD in individuals who request cosmetic surgery (Sarwer et al., 1998) and the DCQ for dermatological treatment (Stangier et al., 2003). Having validated scales which detect DC will enable healthcare professionals in the Spanish-speaking world to make a more accurate diagnosis and prescribe a treatment more suitable to the patient's needs.

\section{AUTHOR CONTRIBUTIONS}

CS-C, SP-G, and JR-T contributed to conception and design of research, analysis and interpretation of data, drafting 
and revising manuscript. MV-D, MB-H, and MN-G contributed to the data collection, setting up the data base, writing and revising the work critically. $\mathrm{RM}-\mathrm{C}$ has been the statistical advisor. All authors read and approved the final manuscript.

\section{REFERENCES}

American Psychiatric Association [APA] (2013). Diagnostic and Statistical Manual of Mental Disorders (DSM 5). Arlington, VA: American Psychiatric Association. doi: 10.1176/appi.books.9780890425596

Anson, M., Veale, D., and de Silva, P. (2012). Social-evaluative versus self-evaluative appearance concerns in Body Dysmorphic Disorder. Behav. Res. Ther. 50, 753-760. doi: 10.1016/j.brat.2012.09.003

Banos, R. M., Belloch, A., and Perpina, C. (1990). Self-consciousness scale: a study of Spanish housewives. Psychol. Rep. 66, 771-774. doi: 10.2466/pr0.1990.66. 3.771

Barahmand, U., and Shahbazi, Z. (2015). Prevalence of and associations between body dysmorphic concerns, obsessive beliefs and social anxiety. Asia Pac. Psychiatry 7, 54-63. doi: 10.1111/appy.12085

Bartsch, D. (2007). Prevalence of body dysmorphic disorder symptoms and associated clinical features among Australian university students. Clin. Psychol. 11, 16-23. doi: 10.1080/13284200601178532

Baumgartner, H., and Homburg, C. (1996). Applications of structural equation modeling in marketing and consumer research: a review. Int. J. Res. Mark. 13, 139-161. doi: 10.1016/0167-8116(95)00038-0

Bjornsson, A., Didie, E., Grant, J., Menard, W., Stalker, E., and Phillips, K. A. (2013). Age at onset and clinical correlates in body dysmorphic disorder. Compr. Psychiatry 54, 893-903. doi: 10.1016/j.comppsych.2013.03.019

Buhlmann, U., Glaesmer, H., Mewes, R., Fama, J. M., Wilhelm, S., Brähler, E., et al. (2010). Updates on the prevalence of body dysmorphic disorder: a populationbased survey. Psychiatry Res. 178, 171-175. doi: 10.1016/j.psychres.2009.05.002

Cash, T. F., and Smolak, L. (2011). Body Image: A Handbook of Science, Practice, and Prevention. New York, NY: Guilford Press.

Castle, D. J., Molton, M., Hoffman, K., Preston, N. J., and Phillips, K. A. (2004). Correlates of dysmorphic concern in people seeking cosmetic enhancement. Aust. N. Z. J. Psychiatry 38, 439-444. doi: 10.1111/j.1440-1614.2004.01381.x

Charter, R. (2003). A breakdown of reliability coefficients by test type and reliability method, and the clinical implications of low reliability. J. Gen. Psychol. 130, 290-304. doi: 10.1080/00221300309601160

Hervás, G. (2008). Adaptación al castellano de un instrumento para evaluar el estilo rumiativo; la escala de respuestas rumiativas [Adaptation to Spanish of an instrument to evaluate the ruminative style; Ruminative Responses scale]. Rev. Psicopatol. Psicol. Clín. 13, 111-121. doi: 10.5944/rppc.vol.13.num.2.2008.4054

Hoek, H. W. (2006). Incidence, prevalence and mortality of anorexia nervosa and other eating disorders. Curr. Opin. Psychiatry 19, 389-394. doi: 10.1097/01.yco. 0000228759.95237 .78

Hollingshead, A. A. (1975). Five Factor Index of Social Position. New Haven, CT: Yale University.

Keating, C., Thomas, N., Stephens, J., Castle, D. J., and Rossell, S. L. (2016). Dysmorphic concern is related to delusional proneness and negative affect in a community sample. Psychiatry Res. 240, 76-79. doi: 10.1016/j.psychres.2016. 03.052

Lavell, C. H., Farrell, L. J., and Zimmer-gembeck, M. J. (2014a). Do obsessional belief domains relate to body dysmorphic concerns in undergraduate students? J. Obsessive Compuls. Relat. Disord. 3, 354-358. doi: 10.1016/j.jocrd.2014.10.001

Lavell, C. H., Zimmer-Gembeck, M. J., Farrell, L. J., and Webb, H. (2014b). Victimization, social anxiety, and body dysmorphic concerns: appearancebased rejection sensitivity as a mediator. Body Image 11, 391-395. doi: 10.1016/ j.bodyim.2014.06.008

Lobo, A., Perez-Echeverria, M. J., and Artal, J. (1986). Validity of the scaled version of the general health questionnaire (GHQ-28) in a Spanish population. Psychol. Med. 16, 135-140. doi: 10.1017/S0033291700002579

Lorenzo-Seva, U., and Ferrando, P. J. (2006). FACTOR: a computer program to fit the exploratory factor analysis model. Behav. Res. Methods 38, 88-91. doi: 10.3758/BF03192753

\section{SUPPLEMENTARY MATERIAL}

The Supplementary Material for this article can be found online at: http://journal.frontiersin.org/article/10.3389/fpsyg. 2017.01107/full\#supplementary-material

Mastro, S., Zimmer-Gembeck, M. J., Webb, H. J., Farrell, L., and Waters, A. (2016). Young adolescents' appearance anxiety and body dysmorphic symptoms: social problems, self-perceptions and comorbidities. J. Obsessive Compuls. Relat. Disord. 8, 50-55. doi: 10.1016/j.jocrd.2015.12.001

Muñiz, J., Elosua, P., and Hambleton, R. K. (2013). Directrices para la traducción y adaptación de los tests: segunda edición [Guidelines for test translation and adaptation: second edition]. Psicothema 25, 151-157. doi: 10.7334/ psicothema2013.24

Nolen-Hoeksema, S., and Morrow, J. (1991). A prospective study of depression and posttraumatic stress symptoms after a natural disaster: the 1989 Loma Prieta Earthquake. J. Pers. Soc. Psychol. 61, 115-121. doi: 10.1037/0022-3514.61. 1.115

Onden-Lim, M., and Grisham, J. R. (2013). Intrusive imagery experiences in a high dysmorphic concern population. J. Psychopathol. Behav. Assess. 35, 99-105. doi: $10.1007 /$ s10862-012-9318-1

Onden-Lim, M., Wu, R., and Grisham, J. R. (2012). Body image concern and selective attention to disgusting and non-self appearance-related stimuli. Body Image 9, 535-538. doi: 10.1016/j.bodyim.2012.07.005

Oosthuizen, P., Lambert, T., and Castle, D. J. (1998). Dysmorphic concern: prevalence and associations with clinical variables. Aust. N. Z. J. Psychiatry 32, 129-132. doi: 10.1046/j.1440-1614.1998.00377.x

Pavan, C., Simonato, P., Marini, M., Mazzoleni, F., Pavan, L., and Vindigni, V. (2008). Psychopathologic aspects of body dysmorphic disorder: a literature review. Aesthetic Plast. Surg. 32, 473-484. doi: 10.1007/s00266-008-9113-2

Phillipou, A., and Castle, D. (2015). Body dysmorphic disorder in men. Aust. Fam. Physician 44, 798-801.

Phillips, K. A. (2009). Understanding Body Dysmorphic Disorder: An Essential Guide. New York, NY: Oxford University Press, Inc.

Phillips, K. A., Menard, W., Fay, C., and Weisberg, R. (2005). Demographic characteristics, phenomenology, comorbidity, and family history in 200 individuals with body dysmorphic disorder. Psychosomatics 46, 317-325. doi: 10.1176/appi.psy.46.4.317

Reiter, J. (1996). Development of the Body Dysmorphic Disorder Examination Interview and Self-Report. Doctoral dissertation, University of Vermont, Burlington, NJ.

Rodin, J., Silberstein, L., and Striegel-Moore, R. (1984). "Women and weight: a normative discontent," in Nebraska Symposium on Motivation Nebraska Symposium on Motivation, ed. T. Sonderegger (Lincoln NE: University of Nebraska Press), 267-307.

Rodríguez-Testal, J. F. (2013). Alteraciones de la Imagen Corporal. Madrid: Síntesis. Rosen, J. C., and Ramirez, E. (1998). A comparison of eating disorders and body dysmorphic disorder on body image and psychological adjustment. J. Psychosom. Res. 44, 441-449. doi: 10.1016/S0022-3999(97)00269-9

Sarwer, D. B., and Crerand, C. E. (2008). Body dysmorphic disorder and appearance enhancing medical treatments. Body Image 5, 50-58. doi: 10.1016/j. bodyim.2007.08.003

Sarwer, D. B., Wadden, T. A., Pertschuk, M. J., and Whitaker, L. A. (1998). Body image dissatisfaction and body dysmorphic disorder in 100 cosmetic surgery patients. Plast. Reconstr. Surg. 101, 1644-1649. doi: 10.1097/00006534199805000-00035

Scheier, M. F., and Carver, C. S. (1985). The self-consciousness scale: a revised version for use with general populations1. J. Appl. Soc. Psychol. 15, 687-699. doi: 10.1111/j.1559-1816.1985.tb02268.x

Schermelleh-Engel, K., and Moosbrugger, H. (2003). Evaluating the fit of structural equation models: tests of significance and descriptive goodness-of-fit measures. MPR Online 28, 23-74.

Schieber, K., Kollei, I., de Zwaan, M., and Martin, A. (2015). Classification of body dysmorphic disorder - What is the advantage of the new DSM-5 criteria? J. Psychosom. Res. 78, 223-227. doi: 10.1016/j.jpsychores.2015. 01.002 
Solano, N., and Cano, A. (2010). Imagen. Evaluación de la Insatisfacción con la Imagen Corporal [Image. Assessment of Dissatisfaction with Body Image]. Madrid: TEA.

Stangier, U., Janich, C., Adam-Schwebe, S., Berger, P., and Wolter, M. (2003). Screening for body dysmorphic disorder in dermatological outpatients. Dermatol. Psychosom. 4, 66-71. doi: 10.1159/000072194

Taqui, A. M., Shaikh, M., Gowani, S. A., Shahid, F., Khan, A., Tayyeb, S. M., et al. (2008). Body Dysmorphic Disorder: gender differences and prevalence in a Pakistani medical student population. BMC Psychiatry 8:20. doi: 10.1186/1471244X-8-20

Valdés-Díaz, M., Núñez-Gaitán, M. C., Rodríguez-Testal, J. F., Benítez-Hernández, M. M., and Senín-Calderón, C. (2013). "Características psicométricas de la escala DCQ de trastorno dismórfico corporal [Psychometric characteristics of the DCQ scale of body dysmorphic disorder]," in VI Congreso Internacional y XI Nacional de Psicología Clínica, eds D. Salas-Castro, T. Ariza, M. M. SánchezFuentes, and R. A. Caparrós-González (Granada: Asociación Española de Psicología Conductual [AEPC]), 549.

Veale, D., Gledhill, L. J., Christodoulou, P., and Hodsoll, J. (2016). Body dysmorphic disorder in different settings: a systematic review and estimated weighted prevalence. Body Image 18, 168-186. doi: 10.1016/j.bodyim.2016. 07.003

Webb, H. J., Zimmer-Gembeck, M. J., Mastro, S., Farrell, L. J., Waters, A. M., and Lavell, C. H. (2015). Young adolescents' body dysmorphic symptoms: associations with same- and cross-sex peer teasing via appearance-based rejection sensitivity. J. Abnorm. Child Psychol. 43, 1161-1173. doi: 10.1007/ s10802-014-9971-9

Conflict of Interest Statement: The authors declare that the research was conducted in the absence of any commercial or financial relationships that could be construed as a potential conflict of interest.

Copyright (c) 2017 Senín-Calderón, Valdés-Díaz, Benítez-Hernández, Núñez-Gaitán, Perona-Garcelán, Martínez-Cervantes and Rodríguez-Testal. This is an open-access article distributed under the terms of the Creative Commons Attribution License (CC BY). The use, distribution or reproduction in other forums is permitted, provided the original author(s) or licensor are credited and that the original publication in this journal is cited, in accordance with accepted academic practice. No use, distribution or reproduction is permitted which does not comply with these terms. 